\title{
Respecting the Aging Self: Communication in the Nursing Home
}

\author{
Research Fellow \\ National Ageing Research Institute, Parkville, Victoria, Australia \\ j.tinney@bigpond.com
}

Jean Tinney, Ph.D.

\begin{abstract}
This article draws on findings of an ethnographic nursing home study that explores the role of communication in maintaining residents' sense of self. These findings suggest that the nursing home can be a site for recovery for the aging self, despite loss and bereavement and the negative effects on self-esteem of pain, illness and loss of function. However, where care privileges the body over social and emotional needs, residents have inadequate opportunities for communication essential to make sense of being old and in care. The key to sustaining the aging self is empathetic communication that recognizes the individuality and value of each older person, no matter how reduced by present illness or incapacity, and at the same time respects residents' rights of choice and personal control. Harried staff, often well-intentioned but unsupported by management, carry an unfair burden. Frequently called upon to do more with less, they find themselves faced with the competing pressures of work routines and residents' emotional needs. In trying to balance these competing needs and provide opportunities for residents to exert personal control over their lives, they must protect both the residents and themselves from the results of "wrong" choices.
\end{abstract}

\section{Introduction}

Many nursing home residents suffer from loneliness and loss of self-esteem. Contributing factors include bereavement and loss of previous social roles and relationships. Attempts to form new relationships with other residents may be undermined by pain, illness, and loss of physical, cognitive, and communicative capacity. Lack of emotional support and opportunities for relational communication can threaten residents' sense of self and increase their levels of dependence. Conversely, close relationships offer enjoyment, meaning, and purpose in life, enhancing health and wellbeing (O'Hanlon and Coleman 2004).

In the absence of family or close friends, staff might appear to be the most readily available conversation partners, but the conflicting demands of their work routines can limit their capacity to explore and try to meet the emotional needs of residents. Staff may also hold negative stereotypes of aging or lack the skills and awareness to recognize the impact of their own communication styles, attitudes, and behavior on residents' self esteem and personal control.

In optimal circumstances, staff will be supported by management with a philosophy of holistic care, and institutional routines that foster person-centered practice. Such a model implicitly recognizes the whole person, and, in so doing, recognizes the history behind that person. It also entails concepts of respect, dignity and self-worth. Ideally, a written Code of Ethics encapsulating such a philosophy will express the commitment of management and provide a blueprint for staff training. In such circumstances the nursing home is a potential site of growth and recovery of the diminished aging self (Nussbaum et al. 2000).

In this article I explore staff perceptions of their role in meeting residents' communication needs, and their commitment to a Code of Ethics that "encourages personal independence in everyday life and respects every person's right to privacy, dignity and individual decision making" (In-house Code of Ethics). I explored these perceptions as part of an ethnographic study, which investigated the role of communication in sustaining residents' sense of self and personal control. In discussing my key findings, I argue that empathetic communication of respect is the key to providing care that recognizes and supports the self. I focus on communication as a means of demonstrating this respect, and with it reinforcing resident self-esteem and well-being. The maintenance of resident dignity and personal control, ethically derived, is deliverable via the practices and communication of respect.

\section{Definition of Terms}

Respect is an assumption of competence and worth in another person or in oneself.

Dignity is a personal sense of worth or value. In the absence of reinforcement though demonstrable personal achievement, it may depend on the communication of respect from others.

The aging self, or Kaufman's "ageless self" (1986) reflects the notion of continuity of self throughout the life span. The core self is strengthened by relational communication, and weakened by loss of relationships and communication partners. 


\section{The Study}

This article is based on ethnographic fieldwork in two aged care facilities in Melbourne, Australia administered by the same not-for-profit provider. I chose this organization because of its good reputation for residentcentered care. This choice arose directly from my research goals. I sought to explore the role of communication in strengthening residents' capacity to maintain sense of self and find meaning in being old and in care. My belief, based on the literature and my own observation of other institutions, was that I needed to observe "good" models of care in order to identify the qualities and characteristics that serve to strengthen resident sense of self. This bias means that I make no direct comparisons with sites offering less resident-centered models of care. In the absence of a body of Australian literature on the subject, references are made principally to studies from the United States. My study fills a gap in the literature concerning older people's experience of aging in residential care, the role of communication, and the staff experience of trying to deliver resident-centered care.

\section{The Sites}

The first site had 50 beds for residents with high care needs. It was an old building in an inner suburb, close to the street and surrounded by other buildings. Most rooms had four beds and no en suite bathrooms. These physical limitations made it difficult for staff to safeguard resident privacy. In contrast, the second site of 60 beds in an outer-suburban setting was a relatively new, purposebuilt structure set in spacious gardens. Most rooms were single, and the few shared rooms were for two people only. All rooms had en suite bathrooms, and resident privacy, at least during personal care, was easier to respect.

\section{Methodology}

Theresearch designincluded prolonged participantobservation (for eight months, two days a week at each site) in the role of voluntary assistant to the Allied Health and Activities staff. Additionally, there were interviews and conversationswithresidents(initialrecordedsemi-structured interviews with twelve cognitively and communicatively competent residents), and many follow-up conversations with these and other residents, families and other visitors. The original research design did not include interviews with staff, although implicit in the principal research question were issues of power and control, dependence and autonomy. Important questions about staff attitudes and practices emerged during the first six months of fieldwork, prompting me to request institutional approval to conduct staff interviews. As an active participant-observer, I had developed good relationships with both care and non-care staff. This partly explains why none of the 23 staff I asked for interviews declined, even though the recorded semistructured interviews of 30 to 60 minutes occurred before or after work shifts. Staff informants included nursing staff (from managers to the most junior Personal Care Assistants), Allied Health and diversionary therapists, and kitchen and housekeeping staff. The average age of nursing staff in residential care in Australia is 47 years, and the workforce is predominantly female (only two of my 23 informants were male).

The employer organization had formulated its own Code of Ethics, and made all regular staff aware of it through orientation procedures and on-going inservice workshops. I asked staff general questions about the rewards and challenges of working in aged care, the possibility of meeting residents' communication needs, and the Code of Ethics. I asked for responses to the affirmation that the organization "encourages personal independence in everyday life and respects every person's right to privacy, dignity and individual decision making" (In-house Code of Ethics). I also asked how staff balanced the tension between safeguarding resident autonomy and resident health and safety.

\section{Background}

\section{Communication and the maintenance of the self}

To explain how empathetic and respectful communication reinforces the sense of self, I examine more closely what is entailed in the process of communication. This is especially relevant in an environment where nonverbal communication, particularly through touch and silence becomes salient: "What doesn't get said also has to be heard" (Savishinsky 1991:159). Communication involves recognition of the other person, and, ideally, that recognition involves the whole person. Implicit in such recognition is the capacity to see beyond illness and disability and realize that a person does not need a body to function perfectly to maintain identity (Kaufman 1988).

Communication also carries, beyond the affective message of recognition and acceptance, willingness to engage with the history and the ideas of a partner who is able to express these. The demonstration of interest conveys a positive valuation of the person as a worthwhile conversation partner, and confirms that the story is worth telling and worth hearing. In the warmth of relational communication, conversation partners form bonds that strengthen the relational self (Cohen 1994). I argue that the aging self is reinforced through narration. In the process of making explicit the links between the past and present self is the possibility of making sense of the present, especially a present where losses have diminished self-esteem and sense of purpose (Gubrium 2001, Kaufman 1986). 


\section{Patronizing communication: "aging talk"}

Patronizing communication includes "verbal alterations such as simplified vocabulary and grammar, repetition, over-familiarity, disapproval, non-listening, and altered topic management" (Ryan et al. 2006:130). Other elements are the linguistic characteristics of "secondary baby talk" (Caporael et al. 1981), altered speech pace, volume, stress and intonation. Caporael and colleagues found the positive response of some care receivers to patronizing language was related to their degree of cognitive dependency. Those less dependent preferred other kinds of talk. "Aging talk" (Giles et al. 1994) that highlights incapacity or powerlessness can reinforce dependent behavior, as can "talking down", or using directive parental language (Kayser-Jones 1981, Shield 1988). Patronizing speech is a form of overaccommodation, described within Communication Accommodation Theory (Coupland and Giles 1988). This is an adjusted communication style arising from negative expectations of recipients' communicative capacity. It is likely to be perceived by competent older recipients as infantilizing, and indeed, many receivers are made feel less powerful, less competent and less worthy of respect. However, when genuine caring and nurturing inspire such patronizing communication, it may be less negatively perceived than communication that is controlling (Barker et al. 2004).

The Communication Enhancement Model (CEM) (Ryan et al. 1995) offers an answer to some of the problems highlighted in the Communication Predicament of Ageing (CPA) (Ryan et al. 1986). In CPA, recognition of "old age cues" activates stereotypes (Hummert 1994) that prompt negative expectations of communicative capacity. The CEM instead includes recognition of cues on an individualized basis, and individual assessment of need. This leads to more effective communication with empowerment of both client and provider, and optimizes health, well-being, and competence of the older person. Other perceived benefits are maximized communication skills and opportunities for the client and increased effectiveness and satisfaction for the provider. In their discussion of these models, Barker and colleagues (2004) emphasize the importance of individual assessment, sensitivity, and active listening. In supporting this contention, I argue that respect for the individual conveyed by appropriate communication styles is fundamental to the empowerment and well-being of residents in aged care, but that genuine interest in the stories as well as the rights of residents confirms the value of the storyteller.

\section{Balancing the ledger: obligation and reciprocity}

Communication offers a means of reducing the imbalance in power and agency inherent in the nursing home context. If the resident's conversation is seen to be valued, it is a gift to be offered in exchange for the care received. This is an extension of anthropological theories of exchange: the lack of relationship with strangers imposes a much greater burden of reciprocity on the receiver of care and services than that involved in family care, where the ideal of love produces a notionally balanced reciprocity (Sahlins 1972). Consequently, reciprocity and perceived obligation in the nursing home is a complex issue, connected to the desire of many residents to be liked. As Savishinsky (1991:120) found, feeling productive and being able to reciprocate mattered: "Things that people gave in return for what they got" were important to residents obliged to ask for and accept so much help. Other researchers report that residents' self-esteem and wellbeing are positively or adversely affected by whether they feel they have anything to offer staff, and in some of the worst cases, delivery of care is also affected (Kayser-Jones 1981). Shield (1988:154) concludes that where old people have "little or nothing considered valuable to exchange, dependency increases, and the value of the old person declines". While I found no evidence of loss of resident value in the eyes of staff, and none of differential treatment, there was, nonetheless, a marked desire on the part of the residents to find something to offer to staff and volunteers - even a joke or a story, and it is reasonable to believe that they felt less worthy when they had nothing to exchange.

Communication enhances resident agency. Expressing personal choices is an act of agency and there is empowerment in having them heard and acted on. This recognition of personal control, or autonomy, as a key value in aged care is central to Australian aged care legislation and government ethical guidelines.

\section{Respect as policy: Codes of Ethics}

I maintain that respect provides a viable means for enhancing independence and personal control. This respect, although enacted through local care practices and communication, should also be emphasized at the higher level of government guidelines and Codes of Ethics.

One of the stated purposes of the Australian government ethical guidelines for residential aged care is to encourage providers to develop their own written protocols. Key rights outlined are "the right of individuals to be treated with respect, the right of competent individuals to selfdetermination, and the right to privacy and confidentiality" (Commonwealth Department of Health and Aged Care 2001). These goals are voluntary and self-regulatory, and the extent to which they are put into practice depends on 
the level of awareness, the personal interpretation, and the good will of individual providers. Adequate funding of residential aged care remains a contentious political issue in Australia, unresolved by a number of government inquiries in recent years. While care costs make it increasingly difficult for service providers to meet their objectives, many will cut corners by reducing staff numbers and devoting a smaller proportion of their budget to meeting residents' social needs. Time-centered and task-centered care, rather than resident-centered care, is an attendant risk. Resident rights, including personal independence, cannot be promoted if residents are rendered powerless, either by restrictive institutional structures and practices, or by denial of adult status as expressed through staff attitudes and behavior (Williams and Nussbaum 2001, Nussbaum and Coupland 2004).

\section{Findings: Overview}

Key findings from staff interviews include confirmation of the value of a resident-centered management philosophy and a Code of Ethics communicated to staff at orientation and supported by regular staff development programs. Other findings include staff willingness to commit to relationships with residents, and support for recognition of the individual personality, history and needs of the residents. Staff identified limitations to their capacity to meet residents' communication needs and provide optimal opportunities for respecting resident choices, and limitations to resident privacy. These limitations included time, staffing numbers, and continuity of staffing necessary to enhance opportunities to "know your resident" and be better able to recognize the preferences and choices of residents with impaired speech and cognition.

\section{Limitations to autonomy}

The limitations in resident autonomy are apparent in all of the day-to-day routines of nursing homes. Even the maintenance of clothing requires the assistance of others. Charles, a 94 year-old male resident showed me how the belt-loops on his trousers no longer held his belt. With his trousers no longer held up securely, he was embarrassed and limited in his mobility. The staff I asked for needle and thread were unaware of his problem, and assured me they would have been happy to fix it. His need had not been noticed, and he lacked the assertiveness described by Ryan et al. (2006) to express it. His capacity to have his wishes recognized and carried out failed him at a time when his dignity and self-esteem were threatened.

\section{Limitations to privacy}

Some aspects of the buildings and fittings limited resident privacy. These included shared bathrooms separate from residents' own rooms, and shared bedrooms that made privacy of conversation with visitors or care staff impossible to maintain, even when curtains were drawn to maintain bodily privacy. Shared rooms and open doors meant that personal space and possessions were not safe from intrusion by ambulant but cognitively impaired residents. Many staff expressed a commitment to protecting privacy boundaries, but found this challenging, confirming the findings of Petronio and Kovach (1997).

\section{Discussion of Findings}

\section{Communicating respect: preserving dignity}

All twenty-three staff respondents were aware of their employer's Code of Ethics and the affirmation I chose to discuss. When asked to comment, most expressed support for the goals, although their interpretation of what could or should be achieved varied widely. Kay, a middleaged Allied Health staffer, felt that having a Code of Ethics increased her work satisfaction. She stated, "I think it's crucial. I wouldn't want to work for an organization that didn't believe that". She felt equally strongly about respecting residents' choices: "I think we should all be striving harder to give as many choices as possible, because otherwise the person just doesn't have any dignity left".

This commitment to preserving resident dignity was shared by many staff. Some felt it should underpin every aspect of care delivery, and be the most important lesson for new staff and trainees. It was linked with recognizing resident individuality, getting to know residents well, and treating residents as equals. Richard, a 40-year-old male nurse, condensed his philosophy of care into the word "dignity", also seeing empathetic care as reflective of his own humanity.

In some ways we do meet their communication needs by taking care of their basic needs...it is a communication need, which in actual fact is a reflection of maintaining their dignity. If we are human in the proper sense, everyone tries to maintain their sense of dignity.

Unlike those described by Shield (1988), the residents at these two nursing homes were not viewed or treated alike, or spoken to as non-persons. Although I saw occasional examples of "talking over", a number of the staff vigorously rejected the practice as well as the use of patronizing or infantilizing language. I suggest that it is simplistic to condemn all terms of endearment as patronizing, because it is evident that some residents 
respond well to such language and do not feel diminished by it. For those who have long-term relationships with certain staff, who have always used terms like 'love' and 'dear' themselves, the use of such terms is seen as nurturing, and a mark of solidarity (see also Barker et al. 2004).

\section{Do as You Would be Done By}

Many staff expressed their commitment to treating residents respectfully. Alice, a 50 year-old nurse, advised new trainees:

Just look at these people as your

mother or your father or your grandmother or yourself. What would

you like? Would you like people treating your parent or yourself like a little kid? Just put yourself in their place.

Others echoed this sentiment. They felt that empathetic imagination was the solution to knowing what residents might like when other attempts to learn their wishes failed. If they could not understand speech, or read residents' bodies or faces, they believed that imagining themselves in the other person's shoes would enable them to deliver the best care. For some this was an emotional theme that reflected the degree of attachment they felt for the residents. For others it was a way of providing the best of professional care and of attempting to ensure that all staff consistently delivered this standard of care.

\section{Recognition of the individual}

Staff rejected the labeling of residents by their illness or disability, by not using terms such as a 'Parkinson's' or a 'dementia', a practice described in other studies (KayserJones 1981). This awareness of, and respect for, resident individuality was fostered by the institution and supported in training practices. As Catherine, a middle-aged senior nurse described her approach to staff education:

It's around people actually asking the question of direct care staff: "Do you realize that's a person who has a name, who has a family and has a life, and who has probably contributed significantly to the world that we live in, and in their own world?" So, it's about identifying the older person as somebody specific, and that holistic thing, rather than an old person.

\section{Difficulties around communication: age, disability and the nursing home}

In maintaining that communication is the key to enhancing personal control, I nonetheless recognize very real limitations to communication that takes place in the nursing home context. First, there are institutional barriers, both social and physical. Equally important are individual personal barriers to communication (including resident health, degree of disability, cognitive and communicative capacity, language and culture, and personality). In light of these barriers, staff cooperation is a vital factor, and the influence of staff workloads and routines on their capacity to know and meet residents' communication needs should be carefully considered.

\section{"Knowing" residents' wishes}

All staff supported residents' right to personal decision-making, but many expressed reservations about residents' cognitive and communicative capacity to make and convey decisions. Some felt it was impossible for staff to know or, in some cases, to value the decisions made. They nonetheless respected the need to see each person as an individual. Others considered it worth making every effort to know and execute the wishes of all residents. They made conscious efforts to find ways of communicating which were not demeaning, no matter how impaired the resident. Emily, a 30 year-old diversionary therapist, explained her approach:

When I am communicating with people it is an effort, like I really, really think about the ways, especially people with dementia or Alzheimer's in the later stages... where I am constantly thinking about the best way to approach them in a way that is not going to demean them at all.

Some staff relied heavily on the information provided by families and others recorded in the resident profile upon entry into the nursing home. The institution saw this resident profile as an instrument for respecting resident decision-making. Activities staff kept their own files on individual residents, constantly adding notes arising from casual conversation with the residents, families, other visitors, and other staff.

Staff who felt it was vital to continue to try to communicate even with the brain-injured assumed that non-responsive residents might hear and understand what was said to or about them. They were confident that, given enough time, they could determine what even a severely communication-impaired resident's wishes might be. They concentrated on listening and watching, knowing 
that "sometimes movement alone could be eloquent" (Savishinsky 1991:131). Maria, a middle-aged nurse, expressed her certainty:

It is one thing that I've learned in aged care... is to listen, and to communicate. It doesn't matter what, because there's always a sign, somewhere in their bodies, their eyes, their lips, their hands, their touch, that gives you the answer.

\section{"Know your resident": continuity of staffing}

Most staff believed that knowing residents well was the key to understanding them and anticipating their needs, and this was an important care issue. By comparing their long-term knowledge of residents with other longterm partnerships, they highlighted the part that time and familiarity played in acquiring this knowledge. Jill, a 51 year-old senior nurse, emphasised the importance of continuity of staffing:

There's lots of non-verbal communication that goes on too, so I guess it's like living with a partner where you learn to... know what that person's thinking. I believe, working in an aged care facility, we need familiar faces. We need people that do know what their needs are and get to know the residents, and that's how they get quality care.

This emphasis on staff continuity as a means of enhancing resident care was a recurring theme. Knowing residents well was the key to respecting and empowering them. This included knowing how to address them in ways that engaged them, both in the relationship and in their own care. Vicky, a 45 year-old Allied Health staffer, felt that listening was the most important part of knowing the residents and the means of establishing relationships, "the thing that really makes you click together".

\section{Respect in practice: supporting independence}

Following Kaufman (1988), I argue that loss of personal control is a threat to identity. On the other hand, self-esteem is boosted by validation and an increased sense of personal control. Resident control is increased by encouragement and the opportunity to make autonomous choices, to find roles, routines and responsibilities, and to exert agency even in such actions as saying no to participating in activities (Savishinsky 1991:119).

Many very ill and disabled residents cannot act independently or contribute to their own health care. Their physical dependence is already established, and their selfesteem and any associated health benefits rest on recognition, not of their capacity to act independently, but of their adult status and their basic rights, including the right to have their decisions respected. I argue that the recognition of adult status and positive evaluation of the worth of individual residents and their lives is best conveyed by respectful communication. Staff who communicate this respect, along with positive expectations of capacity and worth, are instrumental in sustaining resident self-esteem. Their encouragement for residents to make decisions and trust carers to help execute them gives residents the confidence to believe that their wishes are worthy of consideration and reinforces resident identity.

To sum up, the degree of personal control that an individual nursing home is able or willing to guarantee individual residents is dependent on a number of factors. These include the philosophy and communication practices of that organization, the structures and routines, the staffing mix and levels of staff training and experience, and the degree to which the home provides an environment in which staff are encouraged and assisted to consider residents' dignity, privacy, and personal choices. Staff need to know the residents well and these relationships have to be empathetic enough that respect for residents' rights directs the execution of residents' choices.

\section{Staff-resident relationships}

Staff-resident relationships are crucial to reducing the "autonomy-restricting aspects" of the nursing home (Foldes 1990:34). My findings confirm the existence of meaningful staff-resident relationships, the willingness of staff to enter into these relationships, and staff belief in the beneficial effect on residents of care delivered with respect. Indeed, as Aroskar et al. (1990:278) suggest, "given the intimate nature of the care required, it is hard to believe that personal care could be rendered happily or received comfortably in the absence of some relationship of mutual respect".

\section{Emotional dependence}

Staff, while willing to form relationships, also faced the question of how they could best respect and protect the residents in their care from emotional dependence. There is no easy answer to this question. The relationship between staff and residents is inherently unequal, given staff responsibility for resident health and safety and the dependence of residents on staff for all of their care needs. They live in a closed world, and residents are vulnerable and relatively powerless. Thoughtful staff are aware of the risk of increasing resident dependency through building social relationships that are too close and absorbing. Nina, a 
middle-aged nurse manager, recognized that "you become people's life" and try to handle that gift responsibly. Staff felt they could help to reduce the power imbalance by not using patronizing language or doing so much for residents that they were discouraged from helping themselves (as described by Baltes and Wahl 1992). Remembering to acknowledge and spend time with the more independent residents was also important. Some of my informants saw residents almost as family and were proud to be part of their lives, suffering when residents died, but considering the investment worth the pain. Others preferred to not become too close. With these variations, there was a general conviction that knowing individual residents well enough to establish effective communication was the key to furthering resident independence. This finding supports the Communication Enhancement Model (Ryan et al. 1995)

\section{The Time Factor}

Even with the confidence that they could always communicate with residents they knew well enough, staff saw time as the most significant barrier. Getting to know residents with physical or cognitive challenges takes time and great patience. Staff needed time to be with residents; to learn their likes and dislikes; to gain their trust; to make contact with the hearing impaired; and above all, to listen to what the residents' voices or bodies were trying to communicate, especially in cases of physical incapacity. Barbara, a 52 year-old senior nurse, explained: "It is timeconsuming. You might have to wait for five minutes for a long blink to give an affirmative answer, so it is time consuming". Time was seen as the main obstacle to their being able to know and execute residents' wishes. Savishinsky (1991) reported similar findings, including staff regret that they lacked time to show compassion. Alice described the pressure imposed by trying to balance conflicting imperatives:

I think that's probably one of the worst things about it, that you don't have the time to actually understand, to stand there and... when you do make yourself stand there and listen to what they're going to say, all the time I'm thinking, "Oh, I've still got so many other medications to give out".

Explicit in these words is the conflict felt between the sense of medical professional duty and that of recognizing social needs and the resident's right to be heard. Staff were willing to be patient, but the pressures of attending to medical needs limited the time available to build relationships. This highlights the basic dilemma of the conflicting roles of a nursing home (Foldes 1990). If it is considered primarily a medical facility, then professional care goals will inevitably take precedence over social needs. If it is perceived as a residence, then social needs will take a higher priority, as will concern for resident autonomy.

Time is an important factor in communicating with the cognitively impaired, with thoughtful staff anxious not only to communicate effectively, but to communicate respectfully, as far as possible in meaningful ways. As Kay explained it:

We always seem to be rushing from one thing to the other. Then because you can't really rush when you have someone with a dementing illness, you have to sit down, be on their eye level, and make it meaningful.

Many staff felt the effort well worth making, even if they could not know what meaning the interaction held for such residents. Emily confirmed her commitment: “Once again I feel like sometimes they don't have to be meaningful for me...but meaningful to them."

\section{The balancing act: Resident independence versus Duty of Care}

Some staff interpreted the aspect of the Code of Ethics that "encourages personal independence in everyday life" literally, referring to Activities of Daily Living. They encouraged residents to take part in their own daily hygiene routines and in eating and drinking. Others encouraged residents to maintain strength and mobility and participate in social activity. Most saw individual decision making as part of personal independence, and supported the ideal. However, the list of limitations to resident selfdetermination included safety issues, other people's rights, residents' own physical or intellectual capacities, lack of time for staff to determine residents' wishes, and, above all, lack of resources to implement these wishes. Some were very frank about recognizing that they were in control, and that autonomy in aged care was very much something to be granted, or "allowed to happen" rather than something residents could automatically claim. The word "give" in the context of "give them autonomy" and "give them choices" also highlights the power of the staff to control both the expression of resident choices and the execution of those choices. Barbara summarized the staff dilemma:

We've got a duty of care and to be responsible for people's safety and security ....and also if it impacts negatively on other people. And I think we all like to think: "Yes, we give them a choice", probably at the end of the day we're still in control to a certain 
extent. But yes, you can, and again,

it's not easy to give autonomy because

again you've still got to be aware of

their needs.

Staff have a duty, both legal and moral, to preserve resident health and safety, to protect residents from adverse effects of their own behavior, and residents from others' behavior. They are required to be responsible for decisions about care, as opposed to residents who are not. This is epitomized in Barbara's conclusion that extra staff and extra time are probably the keys to furthering resident autonomy, still expressed in terms of staff control, "to be able to let them, allow them to do whatever it is that they need to do for their independence".

The balancing of resident independence against concerns for Duty of Care cannot be divorced from two key issues. One is the quality of resident-staff relationships and the other is the degree of reconciliation between medical and social understandings of the nature and role of the nursing home. When old people are stereotyped as pathetic, powerless, and mentally incompetent, risk factors may seem much greater and the need for protection consequently greater, justifying the denial of autonomy. Residents are often angered and distressed by the denial of what they see as their right to make their own choices and this has a profound effect on their well-being and quality of life. Staff were well aware of this. Kay, explaining how she understood Dignity of Risk and Duty of Care, emphasized the importance of accepting that accidents happen to everybody, but of reducing foreseeable risk factors so that residents' choices can be executed and their autonomy protected as safely as possible. Her understanding of autonomy included assisting the resident "to live a full life as a human being".

\section{"At the end of the day you can only do what you think's best"}

In balancing risk factors against residents' wishes, staff had to decide how important a perceived risk factor was. They tried to involve the resident in the decision, or at least to make clear their reasons for making the decision themselves. The words "let them do what they want" are a reminder of the custodial aspects of nursing home care and the control ultimately held by staff. Different aspects of resident health and safety emerged in interviews. Some staff felt that they needed to intervene if residents chose not to bath or shower, or to get out of bed. This was justified as acting for their own sake. Others were concerned with perceived safety risks, particularly those involved in residents' desire to leave the building unaccompanied. Most of those who wanted to leave were cognitively impaired, and lacked the capacity to perceive or weigh up the magnitude of the risks involved. When staff believed that a resident was incapable of making a rational decision there was less weighing up, but more need for strategies which enabled them to distract or deflect the resident who wanted to act "dangerously". All staff believed that they should not simply refuse residents' requests, and had a range of strategies for dealing with denial of autonomy with as little conflict and as much respect as possible. Kay noted:

But you have to treat it with dignity as well, you have to know ways where you can coax a person away from a door situation where it's not being closed in their face, where it's being done with subtlety and gentleness as well.

The time factor emerged as a reason for not spending too long making decisions, or debating decisions with residents. When staff felt that there was a safety risk they tended to act rather than deliberate. Barbara felt that

There's all sorts of issues in this environment and you'll never get the staffing. That would be just impossible to get the staffing mix that you need to cater for all of these things. At the end of the day you can only do what you think's best. Do your best, I mean, and make sure that everyone's safe and warm and comfortable and as happy as they can be.

The pessimism reflected in "you'll never get the staffing" reflects some of the realities of the current Australian situation, particularly the budget restrictions and staff shortages. My informants knew what they would like to do for residents, and that included assisting them in their independent decision-making and in carrying out their wishes where possible, but they did not feel they could meet resident needs as well as they wished. The lack of adequate staffing limited the time they had to devote to meeting residents' communication needs. In the interim, they were obliged to make their own judgements and accept compromises. I argue that these compromises mean that our potential as a society to deliver care which best respects the aging self and gives meaning to being old is also compromised.

\section{Acknowledgement}

This research was conducted through the Centre for Health and Society in the Faculty of Medicine at the University of Melbourne, Victoria, Australia. 


\section{References Cited}

Aroskar, Mila Ann, Ene Kristi Urv-Wong, and Rosalie A. Kane

1990 Building an Effective Caregiving Staff:

Transforming the Nursing Service. In

Everyday Ethics: Resolving Dilemmas in Nursing

Home Life, R. A., Kane and A. L. Caplan, ed. New

York: Springer Publishing Co.

Baltes, Margret M., and Hans-Werner Wahl 1992 The Dependency-Support Script in Institutions: Generalization to Community Settings. Psychology and Aging 7: 409 - 418.

Barker, Valerie, Howard Giles, and Jake Harwood 2004 Inter- and Intragroup Perspectives on Intergenerational Communication. In Handbook of Communication and Aging Research, J.F. Nussbaum and J. Coupland.. Marwah, N.J.: Laurence Erlbaum Associates.

Caporael, L.R.

1981 The Paralanguage of Caregiving: Baby Talk to the Institutionalized Elderly. Journal of Personality and Social Psychology 40(5):876-884.

Commonwealth Department of Health and Aged Care,

Canberra

2001 Code of Ethics and Guide to Ethical Conduct for Residential Aged Care. Pp 1-11. Canberra: Public Affairs, Parliamentary and Access Branch

Coupland, Nik, and Howard Giles

1988 Communication Accommodation Theory: Recent

Developments. Language and

Communication - special issue (8), 3/4.

Foldes, Steven F.

1990 Life in an Institution: a Sociological and

Anthropological View. In Everyday Ethics: Resolving

Dilemmas in Nursing Home Life, R. A. Kane and A. L.

Caplan, ed. New York: Springer Publishing Co.

Giles, Howard, Susan Fox, Jake Harwood, and Angie

Williams

1994 Talking Age and Aging Talk: Communicating through the Life Span. In Interpersonal

Communication in Older Adulthood: Interdisciplinary Theory and Research, M. L. Hummert, J. M. Wiemann and J. F. Nussbaum, ed. Thousand Oaks, Calif.: Sage Publications.

Gubrium, F. Jaber

2001 Narrative, Experience and Aging. In Narrative

Gerontology: Theory, Research

and Practice, G. M. Kenyon, P. G. Clark \& B. De Vries, ed. Pp. 19-30. New York:

Springer Publishing Company.

Hummert, Mary Lee

1994 Stereotypes of the Elderly and Patronizing
Speech. In Interpersonal Communication in Older Adulthood: Interdisciplinary Theory and Research, M. L. Hummert, J. M. Wiemann and J. F. Nussbaum, ed. Thousand Oaks, Calif.: Sage Publications.

Kaufman, Sharon R.

1986 The Ageless Self : Sources of Meaning in Late Life, Life Course Studies. Madison, Wis.: University of Wisconsin Press.

1988 Stroke Rehabilitation and the Negotiation of Identity. In Qualitative Gerontology, S. Reinharz \& G.D. Rowles, ed. Pp. 82-103. New York: Springer.

Kayser-Jones, Jeanie

1981 Old, Alone, and Neglected. Berkeley: University of California Press.

Nussbaum, Jon F., and Justine Coupland 2004 Handbook of Communication and Aging Research $2^{\text {nd }}$ ed. Mahwah, N.J.: Laurence Erlbaum Associates.

Nussbaum, Jon F., Loretta F. Pecchioni, James D.

Robinson, and Teresa L. Thompson, 2000 Communication and Aging. 2nd ed, LEA's Communication Series. Mahwah, N.J.: L. Erlbaum.

O'Hanlon, Ann, and Peter Coleman 2004 Attitudes Towards Aging: Adaptation, Development and Growth into Later Years. In Nussbaum, Jon F. and Coupland, Justine. Handbook of Communication and Aging Research. Marwah, N.J.: Laurence Erlbaum Associates.

Ryan, Ellen B., Ann P. Anas, and Daniela B. Friedman 2006 Evaluations of Older Adult Assertiveness in Problematic Clinical Encounters. Journal of Language and Social Psychology 25: 129 -144

Ryan, Ellen B., Howard Giles, G. Bartolucci, and K.

Henwood

1986 Psycholinguistic and Social Psychological Components of Communication by and with the Elderly. Language and Communication 6: 1-24.

Ryan, Ellen B., Mary Lee Hummert, and L. H. Boich 1995 Communication Predicaments of Aging:

Patronizing Behavior towards Older

Adults. Journal of Language and Social Psychology 13: 144-166.

Sahlins, Marshall

1972 On the Sociology of Primitive Exchange. In

Sahlins, Marshall. Stone Age Economics. Pp 185-275.

Chicago: Aldine

Savishinsky, Joel S.

1991 The Ends of Time: Life and Work in a Nursing Home. New York: Bergin and Garvey. 